\title{
AMAZÔNIA AZUL: PENSANDO A DEFESA DO TERRITÓRIO MARÍTIMO BRASILEIRO $^{1}$
}

\author{
Marianne Wiesebron $^{2}$
}

\section{Introdução}

\begin{abstract}
"O Brasil dispõe de uma verdadeira 'Amazônia Azul', em relação à qual, sem dúvida, exerce direitos, mas tem também obrigações de conhecê-la e explorá-la economicamente, de forma racional e sustentável. Consequentemente, as riquezas incalculáveis desse espaço marinho sob jurisdição nacional exigem também um Poder Naval capaz de protegê-las." (Carvalho in LEPLAC 2010)
\end{abstract}

O Brasil, com quase 7500 quilômetros de costa atlântica, é um país diretamente interessado pelos desenvolvimentos que têm a ver com o Oceano Atlântico. Graças aos Arquipélagos de São Pedro e São Paulo, e Trindade e Martim Vaz, especialmente o primeiro, a fronteira marítima do Brasil avança bastante em direção à África. O Arquipélago de São Pedro e São Paulo se situa a $1010 \mathrm{~km}$ do ponto mais próximo da costa brasileira e a $1824 \mathrm{~km}$ da costa africana (Viana 2009, 55).

\footnotetext{
${ }^{1}$ Um primeiro estudo "L'Amazonie bleue et les enjeux et contraintes maritimes du Brésil" foi publicado em Revue Défense Nationale 738 (2011), 45-51.

2 Marianne L. Wiesebron é Professora Associada de História no Departamento de Estudos LatinoAmericanos na Faculdade de Ciências Humanas da Universidade de Leiden. (M.L.Wiesebron@hum.leidenuniv.nl)
} 
Nos últimos anos, o Oceano Atlântico, que desde o início da colonização desempenhou um papel fundamental para o Brasil, se tornou ainda mais crucial para o país devido às riquezas que se encontram na Zona Econômica Exclusiva (ZEE) e na Plataforma Continental (PC). Esses conceitos foram definidos pela Convenção das Nações Unidas sobre o Direito do Mar (CNUDM) em 1982 e se tornaram cruciais com a descoberta de enormes jazidas de petróleo e gás em grandes profundidades do Oceano. (Martins 2010, 84-86; Assad 2010, 49-50). ${ }^{3}$

Entretanto, apesar de $80 \%$ da população brasileira viver perto do litoral, a importância do Oceano não está enraizada no Brasil. Especialmente durante o século XX, a preocupação foi assegurar a ocupação de todo o território com suas dimensões continentais, de estimular a povoação e as atividades econômicas para o oeste, e de cuidar das fronteiras terrestres. A decisão de construir uma nova capital no centro do país - Brasília, inaugurada em 1960 - foi a expressão emblemática dessa estratégia. Há muita atenção à Amazônia Verde e suas riquezas, mas não pelas riquezas no mar, que são pelo menos tão diversificadas e importantes, se não mais, para o desenvolvimento do Brasil.

Por essa razão, em 2004 a Marinha do Brasil lançou o conceito de Amazônia Azul, que se tornou marca registrada em 2010. Para salientar a importância do mar, o Ministério da Educação, em colaboração com a Comissão Interministerial para os Recursos do Mar (CIRM), elaborou dois livros: "O Mar no Espaço Geográfico Brasileiro" e "A Importância do Mar na História do Brasil", publicados em 2005 e 2006, respectivamente. ${ }^{4}$ A tiragem de cada volume foi de 177 mil livros, para a distribuição aos professores no ensino fundamental e médio. Entretanto, os atlas brasileiros editados posteriormente ainda não apresentavam nem a Amazônia Azul, nem todos os vários arquipélagos. ${ }^{5}$ Não se trata somente de alertar o governo ou a população a

\footnotetext{
${ }^{3}$ A CNUDM foi estabelecida em 1982 e mais de 156 países ratificaram esta convenção. O Brasil assinou-a em 1982, ratificando-a em 1988. Os EUA assinaram-na, mas não a ratificaram, como evidenciado pela Marinha do Brasil. Para definição de conceitos que dizem respeito à CNUDM, ver, por exemplo, Souza 1999.

4 O Mar no Espaço Geográfico Brasileiro," Coleção Explorando o Ensino 8. Brasília: Ministério da Educação, 2005; “A Importância do Mar na História do Brasil." Coleção Explorando o Ensino 13, Brasília: Ministério da Educação, 2006.

${ }^{5}$ Pesquisa feita em algumas grandes livrarias brasileiras na primeira metade de 2011.
} 


\section{Marianne L. Wiesebron}

respeito da importância da Amazônia Azul: a Marinha do Brasil também precisa estar preparada para novos desafios e poder proteger todas essas riquezas.

Este estudo quer analisar o objetivo desse conceito e quais são as suas consequências para o Brasil, especialmente em nível de segurança (em particular para a Marinha do Brasil), o papel do país no Atlântico Sul e as suas relações com a África Ocidental.

\section{Amazônia Azul}

O termo Amazônia Azul foi lançado para chamar a atenção quanto às imensas riquezas da área oceânica sob a jurisdição brasileira. Essa área abrange a ZEE de 200 milhas náuticas, com uma superfície de $3.539 .919 \mathrm{~km}^{2}$, enquanto a PC, até 350 milhas náuticas, correspondendo a 960 mil km². Somadas, elas abrangem $4.499 .919 \mathrm{~km}^{2}$, ou praticamente 4,5 milhões $\mathrm{km}^{2}$, o que acrescenta uma área marítima equivalente a mais de $50 \%$ da extensão territorial brasileira. $\mathrm{O}$ governo brasileiro pleiteou o reconhecimento da PC na Comissão de Limites da Plataforma Continental (CLPC) das Nações Unidas, apresentando sua proposta em 2004. 6

Após vários intercâmbios com a CLPC, a proposta brasileira foi apresentada de maneira mais aprofundada em março de 2007 à CLPC. Em abril daquele ano, a Comissão respondeu não aceitando 19\% do pleito brasileiro. Por isso está sendo elaborada uma Proposta Revisada de Limite Exterior da Plataforma Continental Brasileira. No meio tempo, a CIRM elaborou a Resolução $\mathbf{n}^{\circ}$ 03/10 em 2010 se outorgando o direito de avaliar pedidos de pesquisas "na sua PC além das 200 milhas náuticas" (More 2010). Porém, essa resolução parece somente confirmar a declaração feita pelo Governo do Brasil em 1982, quando assinou a Convenção das Nações Unidos do Direito do Mar: "I.

O Brasil exerce soberania sobre a Plataforma Continental, para além da distância de 200 milhas náuticas até a borda exterior da margem continental,

\footnotetext{
${ }^{6} \mathrm{O}$ Brasil foi o segundo país a apresentar uma demanda de reconhecimento de Plataforma Continental,
} depois da Rússia, de acordo com a lei da UNCLOS. http://www.mar.mil.br/secirm/leplac.htm 
como definido no Artigo 76." (Declarations or Statements Upon UNCLOS; More 2010)

A previsão é de que em 2012 a CLPC dará uma resposta ao Brasil sobre os $19 \%$ da PC. Essa resposta é crucial porque as recomendações da CLPC estabelecem limites "definitivos e obrigatórios" segundo o artigo 76.8 da Convenção das Nações Unidas Sobre o Direito do Mar (SILVA, 2011: 117). Por enquanto, se está aguardando alguma definição da Comissão. Por ora, nem os $81 \%$ sobre os quais a Comissão não tem problemas estão definidos como parte oficial da PC do Brasil.

No meio tempo, se explora petróleo e gás dentro da Zona Econômica Exclusiva e há ainda outras zonas a explorar dentro da mesma. Contudo, as riquezas se estendem à $\mathrm{PC}$. É na $\mathrm{PC}$, por exemplo, que se descobriram quantidades imensas de petróleo e gás no pré-sal. Do outro lado do Atlântico, na África, também foram descobertas reservas de petróleo e gás em camadas de pré-sal. Essas semelhanças na formação geológica não são estranhas visto que o Brasil e a África formavam parte da Gondwana Ocidental. A Petrobras está desenvolvendo atividades na África, inclusive em áreas de pré-sal da Namíbia e do Gabão (Izundu 2009; Martin et al. 2009; Pre-sal.info 2011; Godói, 2011).

Entretanto, as principais atividades da Petrobras se concentram no Brasil. Durante muitas décadas, o Brasil apresentava carências na produção de petróleo e gás. Graças à forragem em alto-mar, o país se tornou mais que autossuficiente em petróleo e o será em breve quanto ao gás, o qual ainda importa, mesmo que apenas parcialmente. Agora, com a descoberta de grandes reservas de petróleo e gás nas camadas de pré-sal, o país está se tornando um grande produtor mundial de petróleo e deveria passar a ser um dos dez maiores do mundo, porém encontrará alguns desafios tecnológicos a enfrentar (Caroli 2010, 125-128). Quanto ao gás, o Brasil não somente se tornará autossuficiente, mas também exportador dentro de alguns anos.

Existem ainda outras matérias primas a serem exploradas nos fundos do Oceano, na ZEE e, possivelmente, na $\mathrm{PC}$, como nódulos polimetálicos que contêm manganês, níquel, cobre e cobalto; e sulfetos polimetálicos que contêm ferro, zinco, cobre e outros metais. Com a demanda crescente de metais e minerais e o aumento dos preços para essas matérias, o interesse em conhecer melhor os recursos no mar profundo e explorar o que for economicamente viável está crescendo (Martins 2006, 125-131). 
Outro setor que merece ser desenvolvido é a pesca, tanto no Oceano, ao longo do litoral com a produção da aquicultura, quanto na água doce. Isso requer um conhecimento bem maior das riquezas naturais do Oceano e das possibilidades de desenvolver a pesca de maneira sustentável. A biodiversidade do Oceano ainda é pouco pesquisada e registrada. Em todo caso, deve ser protegida e, portanto, a poluição e o lixo tóxico, evitados. Numerosos navios já foram pegos em flagrante desovando lastros poluídos. Uma das ações da Marinha é justamente tentar evitar os despejos ilícitos e outras infrações nas águas de jurisdição brasileira.

No entanto, a pesquisa a ser feita vai bem além da biodiversidade. Os estudos oceanográficos no Brasil começaram em 1934, mas foram retomados apenas em 1946, após a Segunda Guerra Mundial, e se multiplicaram sobretudo no final do Século XX e início do Século XXI. A CIRM tem desempenhado um papel fundamental nesse âmbito já que se dispõe a coordenar a Política Nacional para os Recursos do Mar (PNRM), onde estão detalhadas pesquisa, ciência e tecnologia marinhas que devem ser promovidas (República Federativa do Brasil 2005a). Assim, no dia 24 de novembro de 2011 um navio saiu da cidade de Rio Grande para a Cidade do Cabo com dezesseis pesquisadores de cinco universidades a bordo, com a missão de compreender melhor o papel dos oceanos como absorvedor de dióxido de carbono atmosférico (Rota Marinha 2011). ${ }^{7}$ Mas a CIRM também participou de uma reunião em Fortaleza em 2007 onde foi feito um levantamento de todos os cursos, carga horária, avaliações, regiões do Brasil, projetos de pesquisa, etc., que têm a ver de alguma maneira com o mar. Devido à importância crescente do mar para o Brasil, o país deve ser capaz de formar profissionais e acadêmicos do mais alto nível (Krug e Santos 2007).

Dois projetos de pesquisa merecem uma atenção especial: o centro de pesquisa estabelecido no Arquipélago de São Pedro e São Paulo em 1998, apoiado por cinco ministérios. Pesquisadores se revezam continuamente no arquipélago para que esse seja habitado ou então não seria permitido estabelecer

\footnotetext{
${ }^{7}$ Os pesquisadores têm vínculo com Universidade Federal do Rio de Janeiro, Universidade Estadual do Rio de Janeiro, Instituto de Oceanografia da Universidade Federal de Rio Grande, Universidade Federal de Santa Catarina e Centro de Biologia Marinha da Universidade de São Paulo.
} 
uma ZEE em volta do mesmo. A formação geológica do arquipélago é bem peculiar por se tratar de um complexo de rochas plutônicas com algumas rochas sedimentares, e não de formação vulcânica (Viana 2009, 11, 55-63). O Brasil também quer estabelecer um laboratório oceanográfico em pleno mar, um projeto de três ministérios - Defesa, Ciência e Tecnologia, e Meio Ambiente -, para aprofundar o conhecimento do mar, sobretudo nas áreas de segurança ambiental, desenvolvimento de tecnologia naval e de biotecnologia, além do estabelecimento de um observatório submarino (Maltchik e Oliveira 2011).

Entretanto, para a economia do país, o Oceano desempenha outro papel fundamental: na área do transporte, e isso vai bem além da Amazônia Azul; 95\% do comércio internacional, exportações e importações, é feito por via marítima. O Comandante da Marinha Almirante-de-Esquadra Roberto de Guimarães Carvalho considera a enorme dependência do tráfego marítimo uma grande vulnerabilidade do país, já que alguma interferência com o livre trânsito sobre os mares poderia ter consequências muito graves para a economia do país, incluindo levá-lo "ao colapso" (Carvalho 2004). Além do mais, somente 3\% desse transporte se realiza pela Marinha Mercante brasileira. Grandes investimentos seriam necessários nesse setor para reduzir o uso de armadores estrangeiros, o que tem um peso negativo na balança comercial do país. Outros investimentos substanciais seriam necessários para modernizar os portos do Brasil que não conseguem ser bastante competitivos frente aos grandes portos do mundo (Vidigal 2006, 103-119). Está claro que, para a economia do país, a dependência do Oceano é enorme e vai se tornar ainda maior com o desenvolvimento das imensas riquezas que se encontram no Oceano ou no fundo do mar.

\section{Aspetos de segurança e o papel da Marinha do Brasil}

Essas riquezas têm que ser protegidas. Mas, na Amazônia Azul, os limites das águas jurisdicionais são linhas imaginárias sobre o mar, não demarcadas fisicamente como o são em terra firme (Carvalho 2005, 19). Assim, investimentos de peso são necessários para que a Marinha do Brasil seja capaz de exercer o controle dessas águas e ter o poder de dissuasão em caso de necessidade. No dia 18 de dezembro de 2008, o Governo brasileiro publicou a Estratégia Nacional de Defesa (END), onde são determinadas quais as medidas a tomar para que as Forças Armadas sejam capazes de defender o país e 
fomentar o seu desenvolvimento (Estratégia Nacional de Defesa, 2008). O Governo reconhece que não existe uma tradição no Brasil no que diz respeito à defesa do país, uma vez que o país foi envolvido em poucas guerras e, após a delimitação das fronteiras, não teve confrontos com os seus dez vizinhos. $O$ Brasil sempre disse ter uma vocação pacífica e não precisava dar muita atenção à defesa, mas isso possivelmente está mudando (Peixoto 2010, 155-165). Se o país, que desde o final de dezembro de 2011 se tornou a sexta economia no mundo, quer desempenhar o papel que pretende desenvolver no mundo, a sua Defesa tem que acompanhar o seu crescimento. $O$ funcionamento das Forças Armadas - Marinha, Exército e Aeronáutica - tem que ser repensado a longo prazo. Para se tornar mais eficaz, as Forças Armadas têm que estabelecer um Estado-Maior conjunto e unir as operações das três Forças de maneira mais sistemática do que vem sendo o caso. É necessário ir bem além das esporádicas operações envolvendo as três Forças. Trata-se de realmente chegar à cooperação entre as três Forças para poder aumentar sua eficácia e a capacidade de (re)agir de maneira rápida. As Forças Armadas devem ser organizadas "sob a égide do trinômio monitoramento/controle, mobilidade e presença" (República Federativa do Brasil 2008, 4). Essa organização já pode ser efetuada enquanto se trabalha na modernização e desenvolvimento das Forças Armadas, o que requererá investimentos de peso.

Uma prioridade fundamental é manter a soberania da região amazônica (verde). Nenhuma organização ou ação individual, possivelmente servindo interesses estrangeiros, pode infringir esta soberania. A Amazônia Verde será desenvolvida pelo Brasil (República Federativa do Brasil 2008, $10^{\text {a }}$ diretriz).

Por outro lado, deve-se estimular a integração militar na América do Sul, em particular das bases industriais e de defesa, para se chegar à construção da unidade sul-americana sem a participação de países estrangeiros na região (República Federativa do Brasil 2008, 18 ${ }^{\mathrm{a}}$ diretriz). O Governo faz provavelmente referência à presença militar americana na Colômbia e no Paraguai, esta perto da Tríplice Fronteira, entre outros, e à presença britânica nas Ilhas Malvinas (Sousa e Soligo 2011). A integração permitiria também evitar eventuais conflitos na região e reduzir tensões que existem entre vários países vizinhos da região andina (República Federativa do Brasil 2008; Villa 2010, 91-114). No dia da sua posse como Presidente ( $1^{\circ}$ de janeiro de 2011), 
Dilma Rousseff falou com seu homólogo colombiano e convidou a Colômbia a se tornar sócia do MERCOSUL, o que se tornou pouco provável após a formação do Acordo do Pacífico no mesmo ano, cujo tratado de livre comércio foi assinado entre Chile, Colômbia, México e Peru no ano de 2012. Quanto às Ilhas Malvinas, o Brasil, tanto como os outros países do MERCOSUL e da América do Sul através da União de Nações Sul-Americanas (UNASUL), além da recémformada Comunidade dos Estados Latino-americanos e Caribenhos, apoia a posição argentina.

As relações entre a Argentina e o Reino Unido se tornaram mais tensas após a revogação pelo Presidente Néstor Kirchner da colaboração na Área Cooperativa Especial, estabelecida pelo Presidente Menem e que incluía a prospeç̧ão das riquezas do mar, incluindo petróleo. O crescente investimento britânico em prospeç̧ão do petróleo a partir de 2012 tornou a questão ainda mais grave, com ações da marinha dos dois países e reclamações à CLPC e ao Secretário Geral das Nações Unidas por parte do governo argentino. Aliás, a disputa entre os dois governos não se limita às Malvinas: o conflito se agravou agora que o governo britânico também quer ampliar a plataforma continental desta e de outras ilhas no Atlântico Sul e em mares próximos à Antártida. Assim, ambos os países estão pleiteando áreas que se sobrepõem parcialmente ou até mesmo totalmente (Dodds e Benwell 2010; International Boundaries Research Unit 2010). No curto prazo, enfim, a resolução desta questão parece ainda mais urgente, por mais que seja pouco provável que a mesma seja resolvida de maneira satisfatória para a Argentina. Enquanto isso, em ato de solidariedade com os argentinos, navios com a bandeira das Falklands não poderão ancorar em portos de outros países do MERCOSUL, uma decisão simbólica, já que não haveria problemas se hasteassem outras bandeiras. Porém, se o governo argentino decide tomar ações militares, implicações muito além do plano simbólico poderiam ocorrer para os países integrantes do MERCOSUL e da UNASUL. O governo argentino acha que a presença britânica é uma "relíquia do colonialismo", restos da velha ordem mundial, e que os britânicos estão roubando recursos não renováveis da Argentina (Dodds e Benwell 2010, 578-579).

O caso em questão mostra quantas riquezas estão sendo descobertas e exploradas no Atlântico Sul nessas últimas décadas e como isso também envolve questões de segurança que não se limitam a esses dois Estados, Argentina e 
Reino Unido. A Marinha do Brasil está muito consciente do número de ilhas britânicas que se encontram no Atlântico Sul, além das próprias Malvinas e sua posição estratégica, particularmente a Ilha de Ascensão, que permite controlar o tráfego oceânico, visto que está localizada na parte mais estreita entre o Nordeste do Brasil e a costa ocidental africana (Abreu 2010).

É compreensível, portanto, o papel primordial que o governo brasileiro desempenha na intensificação, ampliação e diversificação do processo de integração da América do Sul. Entre os vários planos merece destaque a Iniciativa para a Integração da Infraestrutura Regional Sul Americana, lançada no ano de 2000 em Brasília, um projeto muito ambicioso para o desenvolvimento da infraestrutura de transporte, energia e comunicações. Entre os numerosos projetos, constam uma estrada ligando os dois oceanos, Atlântico e Pacífico, diversas hidrovias, entre outros. A integração física da região é considerada uma das prioridades do Governo brasileiro. Em 2009, para fortalecer esse aspeto, foi criado o Comitê Coordenador do Conselho SulAmericano de Infraestrutura e Planejamento (COSIPLAN, sigla em espanhol) da UNASUL, cuja primeira reunião teve lugar em 2011 no Rio de Janeiro, com projetos considerados prioritários para o desenvolvimento da região durante os próximos 10 anos. Além da infraestrutura, a energia é outro setor que recebe atenção especial dentro da UNASUL. Outra proposta importante, também uma iniciativa brasileira, é o estabelecimento do Conselho de Defesa SulAmericano, integrando os ministérios responsáveis pela segurança dos 12 países e aprovado em 2008 pela UNASUL. Este Conselho tem vários objetivos: a elaboração de políticas de defesa comuns, a integração das bases industriais e de material bélico, e a realização de exercícios militares conjuntos (Villa e Viana 2010, 99-110). A propósito, é impressionante a quantidade de iniciativas que já está sendo desenvolvida a partir da UNASUL, estabelecida no recente ano de 2004, e cujo tratado constitutivo de 2008 entrou em vigor em 2011.

A importância dos recursos energéticos também é enfatizada na EDN, pois como primeira prioridade para a Marinha é mencionada a defesa pró-ativa das plataformas de petróleo e, de modo mais geral, das áreas de produção de petróleo no mar. A segunda prioridade é defender as águas sob a jurisdição brasileira e o próprio território brasileiro, incluindo as ilhas, os arquipélagos, a costa e os rios. A foz do Rio Amazonas merece atenção especial. Quanto ao 
oceano, o campo de ação das Forças Armadas não se limita à Amazônia Azul, mas abrange também o Atlântico Sul, uma das áreas principais a levar em conta pela defesa (República Federativa do Brasil 2008). Finalmente, na Política da Defesa Nacional (PDN) de 2005 (República Federativa do Brasil 2005a) já se era mencionada várias vezes o quão importante estrategicamente o Atlântico Sul é para o Brasil e o porquê de este ser uma prioridade para a Defesa Nacional (República Federativa do Brasil 2005b). É interessante notar que na PDN de 2005, a Amazônia Azul aparece uma vez, enquanto é nem ao menos mencionada na EDN.

A PDN é um documento fundamental que define o que se espera das Forças Armadas em geral e da Marinha, em particular. É especialmente a Marinha que deve defender a região do Atlântico, com o apoio da Aviação Naval e da Força Aérea. Para desempenhar este papel, é necessário modernizar e aumentar a presença da Marinha. Junto à esquadra localizada no Rio de Janeiro, a criação de uma segunda esquadra é considerada necessária no norte/nordeste do país, devido à atenção especial dedicada à foz do Rio Amazonas. Ambas as esquadras terão o seu próprio porta-aviões, uma variedade de navios em diferentes quantidades, incluindo navios de propósitos múltiplos, navios de apoio logístico e uma divisão anfíbia. Todos estes detalhes estão definidos no Plano de Articulação e de Equipamento da Marinha do Brasil (PAEMB), resultado da EDN, e prevê para o PAEMB, entre 2011 e 2030, projetos de curto, médio e longo, com um financiamento que deve ser substancial para permitir melhorar e aumentar o equipamento atual da Marinha. Além disso, o projeto de modernização não deve terminar em 2030 e é pensado pelo menos até 2047 (Mendonça 2011, 151-162). Aliás, quando se estuda os prazos necessários para equipamentos desejados cuja aquisição foi planejada pela Marinha a fim de defender o Brasil quando necessário, pode-se apenas concordar com Rui Barbosa quando dizia que "esquadras não se improvisam".

O PAEMB faz parte do Plano de Articulação e Equipamentos de Defesa Nacional, o qual ainda tem que ser aprovado Congresso Nacional para se tornar política de Estado. O problema é que, por enquanto, a Defesa não é um tema prioritário e os orçamentos ainda não são adequados (Pesce 2010; id. 2012). Isso tem a ver com a vocação pacífica do Brasil e ausência de inimigos contra os quais o país tem de ser protegido. Outro elemento que pode ajudar a explicar a 
relutância por parte do Congresso é o fato do Brasil ter passado por um regime militar durante cerca de vinte anos (1964-1985) e, com o retorno da democracia, as Forças Armadas perderam espaço. Assim, durante um longo período, o orçamento de defesa no Brasil tem sido da ordem de 1,5\% do Produto Nacional Bruto (PNB). Nos últimos anos, aumentou para 2,5\% do PNB. A maior parte do orçamento é reservada para os gastos em salários, sendo apenas $4 \%$ usados em investimentos na modernização de equipamentos (Villa 2008). O orçamento é relativamente modesto e, no seu primeiro ano no poder, o governo Rousseff começou reduzindo todos os orçamentos para combater a inflação, incluindo este. A maioria dos investimentos permanece concentrada em programas relacionados com os submarinos: o desenvolvimento do ciclo do combustível nuclear e o protótipo do reator para a propulsão de submarino nuclear. O Programa de Desenvolvimento de Submarinos (PROSUB) inclui a construção de quatro submarinos convencionais e um nuclear, com transferência de tecnologia para o país, o estabelecimento de um estaleiro naval e uma base de submarinos em Itaguaí, no Estado do Rio de Janeiro. No orçamento, sobrou algum financiamento para o Programa Antártico Brasileiro (Proantar). O financiamento do Proantar vai se tornar mais substancial em 2012, devido aos problemas graves que ocorreram lá no início do ano $^{8}$. O objetivo é utilizar o submarino nuclear para controlar a Plataforma Continental, juntamente com um submarino convencional. $\mathrm{O}$ submarino nuclear é ligeiramente mais rápido e pode ficar submerso por mais tempo. Navios de patrulha e um sistema de satélite devem controlar toda a Amazônia Azul. Está sendo montado um Sistema de Gerenciamento da Amazônia Azul (SisGAAZ) para a sua defesa e segurança marítima (Maltchik e OLIVEIRA 2011; Mendonça 2011, 158 ). Com todo um sistema de sensores, o SisGAAZ vai monitorar o que acontece na superfície, na subsuperfície e no espaço aéreo das águas jurisdicionais brasileiras e em boa parte do Atlântico Sul. Porque, como diz justamente o Vice-Almirante

\footnotetext{
${ }^{8}$ A base deve ser reconstruída depois de um incêndio na Estação Antártica Comandante Ferraz em fevereiro de 2012, e possivelmente será ampliada. "Medida provisória libera $\mathbf{R} \$ 40$ milhões para recontrução de base na Antártica", 08 de agosto de 2012: <http://www2.camara.gov.br/agencia/noticias/CIENCIA-E-TECNOLOGIA/410843-MEDIDAPROVISORIA-LIBERA-R\$-40-MILHOES-PARA-RECONSTRUCAO-DE-BASE-NAANTARTICA.html>.
} 
Ilques Barbosa Junior, a Amazônia Azul é um espaço tridimensional (Galante 2010a).

O investimento em energia nuclear, não somente para os submarinos, é considerado essencial dentro do quadro da EDN. Trata-se de "desenvolver e dominar a tecnologia nuclear." Para isso, será dado apoio a universidades através do financiamento de bolsas de doutorado e pós-doutorado, tanto em ciência fundamental quanto aplicada. Outra área considerada fundamental é a cibernética - espacial e nuclear. A intenção é assinar parcerias estratégicas relativas a essa área, em particular com países da Comunidade de Países de Língua Portuguesa (República Federativa do Brasil 2008). O governo brasileiro quer desenvolver a pesquisa nuclear o máximo possível, dentro dos limites permitidos pelo Tratado de Não Proliferação, do qual o Brasil é signatário (Peixoto 2010, 163-165).

Uma maneira de acelerar o desenvolvimento da tecnologia no país é exigir a transferência de tecnologia, atualmente uma condição sine qua non, para chegar à cooperação na área da Defesa com o governo brasileiro. Além disso, a construção dos equipamentos deve ser feita no próprio Brasil, e a meta é chegar a produzir unidades para venda, depois de serem atingidas as quantidades consideradas necessárias para a defesa do país. Para chegar a esse resultado, o governo do Brasil assinou parcerias estratégicas na área de Defesa com vários países: Alemanha, França, Itália e Rússia e, em 2010, também com os EUA. Entretanto, os conteúdos dos acordos são muito diferentes e, entre estes, a parceria com a França é considerada a mais elaborada e crucial. Segundo o acordo de parceria assinado entre a França e o Brasil em 2008, o governo francês vai pagar o local de instalação do estaleiro que será transferido ao Brasil após 20 anos. Este é o lugar onde serão construídos os quatro submarinos Scorpene e o submarino nuclear, da classe Ruby. A única diferença será que as armas do submarino nuclear serão convencionais (Moreira 2011, 127149). Porém, se para os submarinos a França é considerada a parceira essencial, para a construção de navios há outros candidatos possíveis, como a Alemanha, por exemplo.

No que se refere aos submarinos, o PROSUB é considerado prioritário e um acordo entre o Brasil e a França foi estabelecido, para o qual se destina a maior parte do orçamento dos equipamentos da Marinha usados para a sua modernização. Para a renovação da frota de superfície da Marinha do Brasil foi 
estabelecido o Programa de Obtenção de Meios de Superfície (PROSUPER). Os detalhes de ambos os programas, incluindo o tipo, a quantidade e o prazo de todos os meios navais que estão projetados, se encontram em um documento apresentado pelo Contra-Almirante Rodolfo Henrique de Saboia durante uma palestra. Constam igualmente perspectivas para a indústria nacional. Aliás, há dois aspetos fundamentais dentro desse projeto de defesa da soberania e de modernização: a transferência da tecnologia e o fortalecimento e o estímulo da indústria de Defesa do Brasil (Freitas 2011; Saboia s.d., 13-15). Diversas empresas de sete países - Alemanha, Coreia do Sul, Espanha, França, Itália, Países Baixos e Reino Unido - mostraram interesse em participar no PROSUPER, aceitando os requisitos de transferência tecnológica e construção dos equipamentos no Brasil. A questão é saber quando haverá os meios suficientes para implementar o programa, já que parte do projeto prevista para 2011 foi adiada para 2012 (Pesce 2011).

Quanto à seleção dos aviões navais, a Marinha espera a decisão da Força Aérea para seguir a mesma escolha. A frota de caças da Força Aérea deve ser modernizada. A bem da verdade, isso deveria ter ocorrido há um bom número de anos. A intenção é comprar cerca de 100 unidades, mas começar com 36, o que representa um orçamento de 4 a 7 bilhões de dólares. A discussão sobre a modernização e qual caça escolher não foi finalizada durante o governo Lula, como era a intenção. Foi adiada para o governo Rousseff, que ainda não tomou uma decisão. Por alguns anos a seleção final esteve limitada a três caças dos quais um seria o escolhido: o Rafale da Dassault, francês; o Gripen NG da Saab, sueco; e o F-18 Super Hornet da Boeing, americano.

A Força Aérea parecia preferir o Gripen, enquanto o então Ministro da Defesa, Jobim, e o Presidente Lula manifestaram interesse pelo Rafale, tendo em conta as excelentes relações com a França e um acordo estratégico assinado entre os dois países. Para se chegar a uma decisão final, uma série de fatores deve ser levada em conta: o preço de compra, o preço por hora de voo, o tempo e controle de custos da aeronave após os voos, a transferência de tecnologia, a produção no Brasil e a possibilidade de vender a posteriori. O Rafale é o mais caro, na aquisição, no uso e na manutenção, mas o Governo francês prometeu uma impressionante transferência de tecnologia, incluindo até mesmo códigos secretos do dispositivo. Porém, tanto a Suécia e os EUA prometeram 
igualmente fornecer uma transferência de tecnologia significativa. No entanto, o Gripen por enquanto só foi elaborado no papel, não existe sequer um protótipo deste avião, e se não houver interessados, ele permanecerá um avião virtual. Tecnicamente, o Super Hornet parece ser o modelo mais avançado. Mas a presença de tecnologia dos EUA, mesmo mínima, pode complicar e até mesmo impedir a venda de caças produzidos no Brasil, como foi o caso em 2005 quando o Brasil não foi autorizado a vender à Venezuela aeronaves ALX Super Tucano fabricados pela Embraer, o fabricante brasileiro de aviões, por causa de seus componentes norte-americanos. $O$ governo da Venezuela acabou comprando aviões na Rússia, uma grande perda para o Brasil.

Assim, em primeiro lugar, o governo do Brasil quer desenvolver sua própria indústria militar, a fim de poder inovar sem ter que recorrer a terceiros; em segundo lugar, para satisfazer suas próprias necessidades; e, em terceiro, posteriormente, produzir para vender a países vizinhos. Para fazer isso, se deve evitar a repetição do caso venezuelano. Entretanto, esses três aviões contêm componentes norte-americanos. Isso implica que se deve negociar com o governo dos EUA para evitar possíveis limitações ao desenvolvimento da indústria militar nacional (Villa 2008; Barbosa 2010, 42-45; Bertonha 2010, 120 121). A pergunta é saber se, enquanto a decisão continua a ser postergada, não se deveria estudar novas opções de caças, uma vez que durante todos esses anos a tecnologia segue avançando e, vista a envergadura do projeto, seria uma pena se um investimento tão enorme fosse feito para caças que se tornariam obsoletos em poucos anos.

Obviamente, a aquisição de tanto material novo também requer grandes investimentos em recursos humanos, com especial atenção para os fuzileiros navais, no caso da Marinha. Segundo a EDN, o governo brasileiro não tem a intenção de abolir o serviço militar, mas, ao contrário, reorganizá-lo para torná-lo mais democrático e para que todas as classes sociais realmente participem - o que não é o caso, atualmente. $\mathrm{Na}$ EDN, a participação mais justa no serviço militar é mencionada diversas vezes. Os números excedentes do alistamento terão que participar do serviço civil em uma região diferente da sua região de origem para uma maior integração do país e da identidade nacional (República Federativa do Brasil 2008). O governo brasileiro está realmente repensando a sua Defesa, e as Forças Armadas estão fazendo o mesmo. No entanto, se, por um lado, o serviço militar obrigatório pode ser útil para a 
construção da identidade nacional, por outro, em um mundo onde o conhecimento tecnológico e a especialização se tornam cada vez mais essenciais, Bertonha sugere ser mais sensato se concentrar no desenvolvimento de bons profissionais bem pagos $(2010,119)$.

Os desafios que a Marinha tem de enfrentar no contexto da Amazônia Azul foram destacados em um seminário nos dias 14 e 15 de outubro de 2010, na Escola de Guerra Naval no Rio de Janeiro. Altas autoridades navais e outras salientaram que a Marinha não deve apenas defender as águas jurisdicionais brasileiras, mas também deve estar presente em todo o Atlântico Sul, já que a maioria dos países africanos, que só conseguiram a independência na segunda metade do século XX, estão ainda construindo as suas instituições e o seu poder militar, insuficiente por enquanto para enfrentar grandes desafios. A exceção é a África do Sul, com a qual o Brasil assinou um acordo de cooperação militar no ano de 2003. As duas Marinhas operam em estreita cooperação, por se tratar de proteger de um lado a fronteira marítima Brasil-África e, por outro lado, as vias de acesso no Atlântico Sul, não somente na direção da África, mas sobretudo as rotas marítimas em direção da Ásia. Essas rotas passam pela África do Sul e são consideradas zonas estratégicas fundamentais para o Brasil. Ademais, a cooperação com a África do Sul está crescendo e em várias áreas devido à cooperação Índia-Brasil-África do Sul (IBAS), oficializada em 2005. Dentro do IBAS, a defesa é uma das áreas de cooperação, tendo sido organizados exercícios conjuntos entre as marinhas dos três países (Bueno 2010).

O Brasil também quer cooperar com outros países africanos, especialmente os ocidentais, e aqueles ricos em petróleo, como Angola, que produz atualmente cerca de $6 \%$ do petróleo mundial. $O$ governo brasileiro gostaria que esses países tomassem as medidas necessárias para proteger as suas Zonas Econômicas Exclusivas e, se for o caso, as suas Plataformas Continentais. Também quer estimular e ajudar esses países a apresentarem as suas demandas de reconhecimento à CLPC. Se o Brasil não cumprir a sua parte e não estiver presente, outros países o farão, como a China, muito presente e ativa na África.

Por outro lado, o Brasil também está consciente de que há duas potências da OTAN presentes no Atlântico Sul, em particular a Britânica, que controla cerca de oito ilhas situadas quase no meio do Oceano, sendo uma delas Ascensão, coordenada junto aos EUA (Galante 2010b). É uma das razões pelas 
quais o Brasil lançou a iniciativa já em 1986, ainda na Guerra Fria, da formação da Zona de Paz e Cooperação do Atlântico Sul (ZOPACAS), um projeto que incorpora 24 países, três na América do Sul e 21 na África. A Assembleia Geral das Nações Unidas reconheceu a ZOPACAS, porém houve votos contra da GrãBretanha, dos Estados Unidos e da França - que tem uma fronteira com o Brasil através da Guiana Francesa -, entre outros. O objetivo da ZOPACAS é evitar a presença de armas nucleares, de armas de destruição em massa e de conflitos externos à região no Atlântico Sul (UN 1986). No contexto pós-Guerra Fria, em 1996, a ZOPACAS foi novamente confirmada, com o acréscimo de direitos humanos e de cooperação política, econômica, científica e cultural. Também se menciona o respeito ao meio-ambiente e a prevenção da pesca ilegal (UN 1996). A existência da ZOPACAS foi usada como argumento no documento Política de Defesa Nacional (PDN), também de 1996, do Governo Fernando Henrique Cardoso, para salientar que, com o final da Guerra Fria, um confronto nuclear parece muito pouco provável... A ZOPACAS, junto com o MERCOSUL e o "estreitamento de relações com os vizinhos amazônicos" estabelece "um anel de paz em torno do país". Assim, o Governo pode concentrar sua atenção no desenvolvimento e no combate contra a desigualdade social, segundo a PDN 1996 (2.10). Esse documento é bem diferente da PDN 2005 e, sobretudo, da Estratégia de Defesa Nacional (EDN) de 2008. O presidente Luiz Inácio Lula da Silva (2003-2010) mudou a perspectiva sobre o papel de defesa para o país e a necessidade de investimento nas Forças Armadas como foi desenvolvido na EDN. Na verdade, a EDN, às vezes, é chamada de Programa de Aceleração do Crescimento (PAC) militar, em comparação com o PAC econômico que Lula lançou no seu segundo mandato para impulsionar o crescimento econômico do Brasil. Trata-se de ter a capacidade de defender o Brasil, do poder de dissuasão, de cuidar da soberania do país na terra e no mar.

A importância do Atlântico Sul para a segurança nacional também tem consequências para as relações com o continente africano, em particular com os países da costa atlântica. Durante a presidência de Lula, as relações com a África não apenas se intensificaram, mas também se ampliaram em um número de casos. Em particular, o Brasil começou a ajudar alguns países africanos a melhorar os seus sistemas de defesa. Na maioria dos casos, o Brasil presta auxílio para a formação de militares profissionais. Em 2010, o então ministro da Defesa, Jobim, também declarou que a Marinha do Brasil daria assistência a 


\section{Marianne L. Wiesebron}

países da África Ocidental quanto à confecção de mapas da Plataforma Continental e delimitação das fronteiras de suas plataformas (Maltchik e Oliveira 2011). O objetivo é conseguir manter o Atlântico Sul sob o controle soberano dos países de ambos os lados desse oceano, na medida do possível.

O presidente Luiz Inácio Lula da Silva (2003-2010) tem estimulado uma cooperação ativa com os países africanos, especialmente países de língua portuguesa e aqueles produtores de petróleo da costa ocidental, onde a multinacional Petrobras também tem grandes interesses, como na Angola e na Nigéria. Por esta razão, o governo brasileiro negociou, em 2010, parcerias estratégicas militares com esses países, principalmente para ajudar a treinar militares (Visentini 2010, 215-236). Trata-se também de evitar que as rotas marítimas sejam restringidas pelos países que exploram petróleo e que desejam criar zonas de exclusão em torno das plataformas. Isso tornaria o transporte, tão crucial, ainda mais caro e demorado. Depósitos de petróleo foram descobertos na Namíbia. Com a Namíbia, a cooperação entre a marinha de ambos os países, que data de 1994, foi reforçada. Em 2010, a primeira turma de fuzileiros navais namibianos foi formada com a ajuda da Marinha do Brasil.

Uma parceria especial e muito antiga existe entre Angola e Brasil. Isso data já da época colonial. O Brasil foi o primeiro país a reconhecer a independência da Angola. As relações com Angola são complexas e bem variadas. O Banco Nacional de Desenvolvimento Econômico e Social (BNDES) abriu uma linha de crédito de 2 bilhões de dólares no final de abril de 2012 para Angola. O país também interessa ao Brasil como grande produtor de petróleo, fornecendo $6 \%$ da produção mundial do hidrocarboneto. Um acordo específico foi assinado em 2010 para o treinamento de militares angolanos, e a assistência tecnológica para a Angola ser capaz de pleitear a sua Plataforma Continental. Outrossim, o país é membro da Comunidade dos Países de Língua Portuguesa (CPLP), criada em 1989. A maioria desses países está situada na África Ocidental, com a exceção de Moçambique (Visentini 2010, 233-234, 236-237). Os países africanos de língua portuguesa formaram a sua própria sub-organização: "Países Africanos de Língua Oficial Portuguesa". A Defesa é umas das áreas de cooperação da CPLP. Os ministros da Defesa se encontram quase anualmente. Em novembro de 2011, se organizou a XIII reunião em Cabo Verde. A declaração final mostra claramente que o Brasil desempenha um papel crucial 
nesse encontro e que os parceiros privilegiados são os países africanos (Declaração Final da XIII Reunião dos Ministros da Defesa da CPLP 2011).

No mesmo ano, o Brasil assinou um acordo de cooperação militar com a Nigéria, em primeiro lugar para proteger as rotas marítimas contra as empresas de petróleo estrangeiras e, em segundo lugar, para estreitar as relações da Nigéria com a Marinha do Brasil. Além disso, o país pode estar interessado nas lanchas escolares desenvolvidas pela Marinha, visando ao transporte de alunos de áreas ribeirinhas para escolas públicas da Região Norte. De modo mais geral, o Brasil estimula os países africanos para que cuidem das rotas de navegação a fim de evitar problemas ao concederem direitos de mineração a empresas internacionais (Poggio 2010).

\section{Considerações finais}

A Marinha do Brasil não está apenas construindo a Amazônia Azul, repensando o Atlântico Sul, a segurança nacional e todos os desafios que decorrem dessas questões: ela quer que o Brasil encontre novamente sua vocação marítima. Ela investe pesado na modernização e expansão de vários aspectos da Força Naval: a Força Submarina, que terá submarinos propulsados por energia nuclear; a Força de Superfície; e a Força Aeronaval, para poder desenvolver seu papel nacional e internacional no Atlântico Sul, ampliando, inclusive, sua cooperação com os países da África Ocidental para tal fim. Tratase de apoiar os países africanos para que o Atlântico Sul seja realmente o "Oceano do Sul", sem que haja a presença do Norte - ou ao menos que essa presença não prejudique os interesses do Sul em geral e do Brasil, em particular.

Para acelerar sua meta de se tornar uma potência marítima nova, a Marinha do Brasil trabalha em estreita colaboração com inúmeros países europeus - sobretudo a França, no momento - para assegurar que o seu equipamento seja adequado e que haja transferência de tecnologia e o estabelecimento da indústria naval de guerra no Brasil. O Ministério da Defesa, as Forças Armadas e, em particular, a Marinha passaram de uma atitude reativa a uma posição muito pró-ativa. A Estratégia Nacional de Defesa desempenha um papel crucial e indica um rumo diferente para o país. Se o país quer assumir o papel de potência mundial, o seu poder militar tem de acompanhar as suas ambições, sobretudo no Hemisfério Sul. 
Para poder realizar esses objetivos, o Governo e o Congresso têm de dar o apoio necessário, em particular financeiramente, para que as Forças Armadas, e, no caso da Amazônia Azul, a Marinha e a Força Aérea estejam preparadas e com os equipamentos modernizados o suficiente para poder cuidar da soberania do país e ter o poder de dissuasão necessário. Trata-se de "preservar a capacidade de um Estado costeiro fortalecer a Segurança Nacional" (Barbosa 2007, 51). O Estado costeiro com uma Amazônia Azul certamente requer ainda mais atenção.

A Presidenta Dilma Rousseff está dando atenção especial à indústria da Defesa, cujo crescimento se faz necessário e, por isso, está estabelecendo medidas específicas para tal objetivo, como a redução de impostos para incentivar essa indústria. $\mathrm{O}$ orçamento, porém, tem que acompanhar os objetivos.

\footnotetext{
"Somos a sexta economia do mundo e queremos ser um país desenvolvido, com elevado índice de desenvolvimento humano. As nossas Forças Armadas também têm de estar à altura do país em meritocracia, profissionalismo, capacidade técnica e, além disso, em capacidade dissuasória" (Rousseff 2012).
} 


\section{REFERÊNCIAS}

Abreu, Guilherme Mattos de. 2010. “A Amazônia Azul: O Mar que nos Pertence.” Diário do Pré-Sal January 01. Acessed May 25, 2012. http://diariodopresal.wordpress.com/2010/02/01/a-amazonia-azul-o-mar-quenos-pertence/.

Assad, Leonor. 2010. "Fronteira marítima. Uma Amazônia pintada de azul." Ciência e Cultura, 62(3).

Barbosa, Enio. 2010. "Programa FX-2 de modernização de caças da FAB pode contribuir para o avanço da indústria nacional." Conhecimento \& Inovação $6(1), 42-45$.

Barbosa Júnior, Ilques. 2007. “A importância do Atlântico Sul para a segurança nacional e integração Regional." Revista da Escola Superior de Guerra, 23(48), 43- 93.

Bertonha, João Fábio, 2010. "Brazil: an emerging military power? The problem of the use of force in Brazilian international relations in the 21 st century." Revista Brasileira de Política Internacional 53(2), 107-124.

Bueno, Adriana Mesquita Corrêa, "Os três pilares institucionais do Fórum de Diálogo Índia-Brasil- África do Sul (IBAS): coordenação política, cooperação setorial e Fundo IBAS." Paper prepared for the VI CEISAL Congress "Independências - Dependências - Interdependências". Toulouse, France, June 30 - July 03, 2010, 8-9. Acessed May 25, 2012. http://halshs.archivesouvertes.fr/docs/00/49/66/29/PDF/AdrianaBueno.pdf.

Caroli, Luiz Henrique. 2010. “A Importância Estratégica do Mar para o Brasil no Século XXI.” CEE-ESG 9, 117-157.

Carvalho, Roberto de Guimarães. "A Amazônia Azul”. Defesa Net, 04 Março 2004. Disponível em: http://www.defesanet.com.br/

. "A outra Amazônia", in O Mar no Espaço Geográfico Brasileiro, Coleção Explorando o Ensino no 8, Ministério da Educação, Brasília, 2005 ,p. 17-19.

Declaração Final da XIII Reunião dos Ministros da Defesa da Comunidade dos Países de $\begin{array}{lll}\text { Língua } \quad \text { Portuguesa } & \text { (CPLP). }\end{array}$ https://www.defesa.gov.br/arquivos/2011/mes12/declaracao.pdf

Declarations or Statements upon

UNCLOS. http://www.un.org/depts/los/convention_agreements/convention_declarations.ht $\mathbf{m}$

Dodds, Klaus and Matthew C. Benwell. 2010 "More unfinished business: the Falklands/Malvinas, maritime claims, and the specter of oil in the South Atlantic." Environment and Planning D: Society and Space 2010, volume 28, p. 571- 580 . 


\section{Marianne L. Wiesebron}

Freitas, Neisser Oliveira, "Instrumentos de Desenvolvimento Nacional", Revista da Escola de Guerra Naval, Rio de Janeiro, v.17 n.1 p.93-114, jan/jun 2011.

Galante. 2010a. "Simpósio discute defesa da Amazônia Azul." Poder Naval, August 26. http://www.naval.com.br/blog/2010/08/26/simposio-discute-defesa-da-amazoniaazul/\#axzzlwpNMi0Uy 2010b. "Poder Naval no Seminário da Amazônia Azul, na Escola Naval." Poder Naval, October 16. http:/www.naval.com.br/blog/2010/10/16/poder-naval-noseminario-da-amazonia-azul-na-escola-naval/

Godoi, Maurício. 2011. “África torna-se nova rival do pré-sal brasileiro.” DCI, January 04. http://www.dci.com.br/Africa-torna-se-nova-rival-do-pre-sal-brasileiro-7356696.html

International Boundaries Research Unit. 2010. "Claims and potential claims to maritime jurisdiction in the South Atlantic and Southern Oceans by Argentina and the UK." Durham University, June 24. http://www.dur.ac.uk/resources/ibru/south_atlantic_maritime_claims.pdf

Izundu, Uchenna. 2009. "Soco spuds Liyeke Marine-1 oil well off Congo." Oil and Gas Journal, August 25. http:/www.ogj.com/articles/2009/08/soco-spudsliyeke.html

Krug, Luiz Carlos and Maria Inês Freitas dos Santos. 2007. I Encontro de Coordenadores de Graduação e Pós-Graduação em Ciências do Mar Fortaleza, Anais. November 2022.

http://www.oceanografia.furg.br/cdmb/upload/file/Anais $\% 20 \mathrm{do} \% 20$ Encograd $\% 2$ 0 (final).pdf

LEPLAC. 2010. Plano de Levantamento da Plataforma Continental Brasileira, Marinha do Brasil. http://www.mar.mil.br/dhn/dhn/quadros/ass_leplac.html

Maltchik, Roberto e Eliane Oliveira. 2011. "Governo planeja ter laboratório oceanográfico em alto-mar para garantir domínio territorial." Oceanografia $\begin{array}{ll}\text { Brasil, January } & 10 .\end{array}$ http://www.oceanografiabrasil.com/oceanografia/governo-planeja-terlaboratorio-oceanografico-em-alto-mar-para-garantir-dominio-territorial

Martin, Jim, et al. 2009. "Presalt basins identified in Gabon: A new study indicates Brazilian analogs". $\boldsymbol{E} \& \boldsymbol{P}$ Magazine, July 01. http://www.epmag.com/Exploration/Presalt-basins-identified-Gabon_41404

Martins, Eliane Octaviano. 2010. “Amazônia Azul, Pré-sal, soberania e jurisdição marítima." Revista CEIXIV(50), 88.

Martins, L.R, E. G. Barboza, and M. L. C. C. ROSA. 2006. "Nódulos Polimetálicos e outros Depósitos de Mar Profundo: o. Retorno do Interesse." GRA VEL (4). 
Mendonça, Luiz Umberto de. 2011. “Aula Inaugural dos Cursos de Altos Estudos da Escola de Guerra Naval no ano de 2011." Revista da Escola de Guerra Naval, 17(1), 151-162.

More, Rodrigo Fernando. 2010. "Quando cangurus voarem: a declaração unilateral brasileira sobre direito de pesquisa além dos limites da plataforma continental." Work Presentation.

Moreira, William de Sousa. 2011. "Obtenção de Produtos de Defesa no Brasil: O Desafio da Transferência de Tecnologia." Revista da Escola de Guerra Naval, 17(1), 127-149.

Peixoto, Bernardo dos Reis, et al. 2010. "Le nouveau plan pour une stratégie de défense nationale du Brésil: la fin d'un état pacifiste?" In Relations internationales du Brésil, Les chemins de la puissance, organized by Denis Rolland \& Antônio Carlos Lessa, v.1, 155-165. Paris: l'Harmattan.

Penha, Eli Alves. 2010. “Os Sistemas de Segurança Regional no Atlântico Sul: da Guerra Fria ao período atual”, 2010 , http://reservaer.com.br/estrategicos/sistemas-seg-regional.html

Pesce, Eduardo Italo. 2010. "Plano de Articulação e de Equipamento da Marinha do Brasil (PAEMB) 2010-2030: Perspectivas." Revista Marítima Brasileira 130 (04/06), 73-88.

. 2011. “Obtenção de meios de superfície para a Marinha." INEST, November 18.
Acessed
May
26 ,
2012.

http://www.inest.uff.br/index.php?option=com_content\&view $=$ article\&id $=2$

86:obtencao-de-meios-de-superficie-para-a-

marinha\&catid=3:industria\&Itemid=79.

. 2012. "Desafios para a Marinha do Brasil nos próximos anos." Poder Naval,

$\begin{array}{lllll}\text { January } & 04 . & \text { Acessed } & 2612 .\end{array}$

http://www.naval.com.br/blog/tag/peamb/\#axzzlwCXXEi00

Poggio, Guilherme. 2010. "Brasil e Nigéria firmam acordo de cooperação militar que prevê exploração mineral no Atlântico." Poder Naval, July 23. http:/www.naval.com.br/blog/2010/07/23/brasil-e-nigeria-firmam-acordo-decooperacao-militar-que-preve-exploracao-mineral-no-atlantico/

Política de Defesa Nacional, Presidência da República, Governo Fernando Henrique Cardoso, Brasília - 1996, www.planalto.gov.br/publi_04/colecao/DEFES.htm

Pré-Sal Info. 2011. "Petrobras no pré-sal da África", June 17. http://presal.info/index.php?option=com_content\&view=article\&id=301:petrobras-nopre-sal-da-africa\&catid=12:noticias\&Itemid=1

República Federativa do Brasil. 2005a. "Decreto n' 5.377, de 23 de fevereiro de 2005." http://www.dji.com.br/decretos/2005-005377/2005-005377.htm 


\section{Marianne L. Wiesebron}

2005b. Decreto $n^{o}$ 5.484, de 30 de junho de 2005. http://www.planalto.gov.br/ccivil_03/_Ato2004-006/2005/Decreto/D5484.htm 2008. Decreto $n^{\circ}$ 6.703, de 18 de dezembro de 2008. Section 1, 4-14. http://www.planalto.gov.br/ccivil_03/_Ato2007-010/2008/Decreto/D6703.htm Rota Marinha. 2011. "UFSC integra equipe brasileira em expedição pelo Atlântico Sul", November 06. http://rotamarinha.wordpress.com/2011/11/06/ufsc-integraequipe-brasileira-em-expedicao-pelo-atlantico-sul/

Rousseff, Dilma. 2012. Discurso da Presidenta da República, Dilma Rousseff, na cerimônia de apresentação de Oficiais- Generais. Speech made at Palácio do Planalto, Brasília, May 08. https://www.defesa.gov.br/arquivos/2012/Pronunciamentos/Presidente_da_re publica/discurso_cerimonia_oficiais_generais_2012.pdf

Saboia, Rodolfo Henrique de, "Programa de Obtenção de Meios de Superfície. Perspectivas para a Indústria Nacional" Palestra, http://www.camaras.org.br/Arquivos/Download/Upload/442.pdf, acesso 26-52012 .

Silva, Alexandre Pereira da. 2011. “A Política Externa Brasileira para os grandes espaços: o espaço cósmico, a Antártida e a expansão da Plataforma Continental." Século XXI, 2(2), 105-117.

Sousa, Joceli de Fatima Arruda and Valdecir Soligo. 2011. "O Brasil, Argentina e Paraguai na agenda de segurança dos Estados Unidos e o mito do terror na Tríplice Fronteira." Anais do V Colóquio Internacional Cultura e Memória Social - August 24-26. http:/cacphp.unioeste.br/eventos/vcoloquio/textos/10__joceli_de_fatima_arruda_sous a.pdf.

Souza, J.M. de. 1999. "Mar territorial, zona econômica exclusiva ou plataforma continental." Revista Brasileira de Geografia 17(1). http://dx.doi.org/10.1590/S0102-261X1999000100007.

United Nations. 1986. General Assembly, Resolution 41/11, Declaration of a zone of peace and co-operation in the South Atlantic, A/RES/41/11, October 27. http://www.un.org/documents/ga/res/41/a41r011.htm 1996. General Assembly, Resolution 51/19, "Zone of peace and cooperation of the South Atlantic", A/RES/51/19, November 25. http://www.un.org/documents/ga/res/51/ares51-19.htm

Vaz, Alcides Costa. 2011. "O Atlântico Sul nas Perspectivas Estratégicas de Brasil, Argentina e África do Sul." Boletim de Economia e Política Internacional, IPEA 6, 63-68. 
Viana, Danielle de Lima, et al. (org.). 2009. O Arquipélago de São Pedro e São Paulo: 10 anos de Estação Científica. Brasília: SECIRM.

Vidigal, Armando Amorim, and Marcílo Boavista da Cunha Ferreira, et al. 2006. Amazônia Azul: o mar que nos pertence. Rio de Janeiro: Record.

Villa, Rafael Duarte. 2008. "Corrida armamentista ou modernização de armamentos na América do Sul: estudo comparativo dos gastos militares." Estudos e Cenários. http://www.opsa.com.br/pdfs/8_estudosecenarios_2008-12\%20$\% 20$ Estudos_Villa.pdf

Villa, Rafael Duarte, and Manuela Trindade Viana. 2010. "Security issues during Lula's administration: from the reactive to the assertive approach." Revista Brasileira de Política Internacional edição especial, 91-114.

Visentini, Paulo Fagundes, 2010. "Prestige Diplomacy, Southern Solidarity or "Soft Imperialism'? Lula's Brazil-Africa Relations (2003 onwards)." In Relations internacionales du Brésil, Les chemins de la puissance, v. 2, 231-245 organized by Dennis Rolland and Antônio Carlos Lessa. Paris: l'Harmattan,

Wiesebron, Marianne L. 2011. "L'Amazonie bleue et les enjeux et contraintes maritimes du Brésil." Revue Défense Nationale 738, 45-51.

. 2012. "Repenser l'Atlantique sud: perspectives du Brésil." In Repenser I'Atlantique : Commerce, immigration, sécurité, edited by Dorval Brunelle, 373-393. Bruxelles, Bruylant. 


\section{Marianne L. Wiesebron}

\section{RESUMO}

A Marinha do Brasil elaborou o conceito Amazônia Azul para alertar sobre as riquezas do Oceano e a sua importância para a economia do Brasil. Isso implica também pensar na defesa dessas riquezas nacionais e nos investimentos necessários para que a Marinha seja capaz de proteger as águas jurisdicionais brasileiras.

\section{PALAVRAS-CHAVE}

Amazônia Azul; Atlântico Sul; Recursos do Mar; Defesa; Segurança; Marinha do Brasil. 